\title{
Article \\ PDF1.5 Enhances Adaptation to Low Nitrogen Levels and Cadmium Stress
}

\author{
Zhimin Wu ${ }^{1,2}$, Dong Liu ${ }^{1,3}$, Ningyan Yue ${ }^{1,3}$, Haixing Song ${ }^{1,3}$, Jinsong Luo ${ }^{1,3, *}$ and Zhenhua Zhang ${ }^{1,3, *(\mathbb{D})}$ \\ 1 Southern Regional Collaborative Innovation Centre for Grain and Oil Crops in China, College of Resources \\ and Environmental Sciences, Hunan Agricultural University, Changsha 410128, China; \\ wuzhimin@caas.cn (Z.W.); liudongzh@163.com (D.L.); yue493790266@163.com (N.Y.); shx723@163.com (H.S.) \\ 2 Institute of Bast Fiber Crops, Chinese Academy of Agricultural Sciences, Changsha 410221, China \\ 3 National Centre of Oilseed Crops Improvement, Hunan Branch, Changsha 410128, China \\ * Correspondence: 0609020317@163.com (J.L.); zhzh1468@163.com (Z.Z.)
}

Citation: Wu, Z.; Liu, D.; Yue, N.; Song, H.; Luo, J.; Zhang, Z. PDF1.5 Enhances Adaptation to Low Nitrogen Levels and Cadmium Stress. Int. J. Mol. Sci. 2021, 22, 10455. https://doi.org/10.3390/ ijms221910455

Academic Editors:

Magdalena Arasimowicz-Jelonek,

Arkadiusz Kosmala,

Ewa Sobieszczuk-Nowicka and Gabriella Szalai

Received: 8 June 2021

Accepted: 5 August 2021

Published: 28 September 2021

Publisher's Note: MDPI stays neutral with regard to jurisdictional claims in published maps and institutional affiliations.

Copyright: (c) 2021 by the authors. Licensee MDPI, Basel, Switzerland. This article is an open access article distributed under the terms and conditions of the Creative Commons Attribution (CC BY) license (https:// creativecommons.org/licenses/by/ $4.0 /)$.

\begin{abstract}
Environmental acclimation ability plays a key role in plant growth, although the mechanism remains unclear. Here, we determined the involvement of Arabidopsis thaliana PLANT DEFENSIN 1 gene AtPDF1.5 in the adaptation to low nitrogen (LN) levels and cadmium (Cd) stress. Histochemical analysis revealed that AtPDF1.5 was mainly expressed in the nodes and carpopodium and was significantly induced in plants exposed to LN conditions and Cd stress. Subcellular localization analysis revealed that AtPDF1.5 was cell wall- and cytoplasm-localized. AtPDF1.5 overexpression significantly enhanced adaptation to LN and Cd stress and enhanced the distribution of metallic elements. The functional disruption of AtPDF1.5 reduced adaptations to LN and Cd stress and impaired metal distribution. Under LN conditions, the nitrate transporter AtNRT1.5 expression was upregulated. Nitrate transporter AtNRT1.8 expression was downregulated when AtPDF1.5 was overexpressed, resulting in enhanced transport of $\mathrm{NO}_{3}{ }^{-}$to shoots. In response to Cd treatment, AtPDF1.5 regulated the expression of metal transporter genes AtHMP07, AtNRAMP4, AtNRAMP1, and AtHIPP3, resulting in higher Cd accumulation in the shoots. We conclude that AtPDF1.5 is involved in the processing or transmission of signal substances and plays an important role in the remediation of $\mathrm{Cd}$ pollution and $\mathrm{LN}$ adaptation.
\end{abstract}

Keywords: abiotic stress; cadmium adaptation; low nitrogen; environment adaptation ability; nutrient element distribution; plant defensin

\section{Introduction}

Environmental acclimation ability plays a crucial role in plant growth, and nutrient element transport is a key factor in environmental acclimation [1-3]. It has previously been shown that plants have a higher nitrogen assimilation efficiency when larger amounts of $\mathrm{NO}_{3}{ }^{-}$are transported to shoots [4]. Shoots are the main sites of photosynthesis and metabolism in plants [5,6], and the translocation of $\mathrm{NO}_{3}{ }^{-}$from roots to shoots has been reported to be one of the main processes contributing to plant growth and higher nitrogenuse efficiency [7]. With respect to $\mathrm{NO}_{3}{ }^{-}$transport, nitrate transporter 1.5 (NRT1.5) is involved in xylem $\mathrm{NO}_{3}{ }^{-}$loading [8], whereas nitrate transporter 1.8 (NRT1.8) functions in xylem $\mathrm{NO}_{3}{ }^{-}$unloading [9]. Accordingly, the NRT1.5 and NRT1.8 genes play important roles in $\mathrm{NO}_{3}{ }^{-}$distribution $[10,11]$.

Metallic elements play vital roles in plant growth and stress resistance [12,13], with different metals having specific functions [14]. In plants, potassium (K) can promote the activation of enzymes and enhance photosynthesis, sugar metabolism, and protein synthesis, thereby enhancing the ability of plants to resist drought, cold, salt, alkaline stresses, diseases, and pests $[15,16]$. Calcium (Ca) is mainly found in plant cell walls, where it functions in stabilizing membrane structure and serves as a secondary messenger in signal transduction [17]. Manganese (Mn) is an essential factor in chlorophyll biosynthesis and 
functions as an activator of enzymes such as transphosphatase (hexokinase), dehydrogenase ( $\alpha$-ketoglutarate dehydrogenase), nitrate reductase, and dipeptidase [18]. Iron $(\mathrm{Fe})$ is absorbed mainly in the form of $\mathrm{Fe}^{2+}$ chelate and functions as a component of enzymes and electron transporters $[19,20]$. Copper $(\mathrm{Cu})$ functions as a component of plastids and as an electron transporter in the photosynthetic chain, thereby contributing to electron transfer and photophosphorylation. $\mathrm{Cu}$ is also a component of enzymes such as cytochrome oxidase, phenoloxidase, ascorbic acid oxidase, polyamine oxidase, and peroxide dismutase involved in respiratory metabolism [21,22].

Concerning metal transporters, it has been reported that more than $30 \%$ of proteins have metallic ion constituents, which play key roles as structural components or catalytic factors [23,24]. Among the proteins known to mediate metal transport are natural resistance-associated macrophage protein-1 (NRAMP1), NRAMP4, and heavy metalassociated isoprenylated plant protein-3 (HIPP3). NRAMP4 is located in the vacuolar membrane and transports metals from the vacuole to the cytoplasm via a proton symporter $[25,26]$. NRAMP1 is present in the plasma membrane [27] and has been shown to play a role in Fe uptake under Fe deficiency conditions [28]. HIPP3 is a nuclear-localized zinc-binding protein that is a member of the detoxification superfamily and is involved in heavy metal transport [29-31]. It is necessary to explore its function for acclimation or defense in environmental change.

Plant defensin (PDF) genes are a class of small molecular proteins, each comprising 45 to 54 amino acids, and at least 13 genes have been identified in Arabidopsis thaliana. PDF genes primarily play roles in fungal resistance and $\mathrm{Zn}$ tolerance [32-35] and can be divided into two families, namely, PDF1 and PDF2. Among the PDF1 family genes, PDF1.2, which can be induced by jasmonate and ethylene, has been reported to play a role in pathogen resistance [35]. In the PDF2 family genes, PDF2.1 has been reported to show tissuespecific expression and affects ammonium metabolism by regulating glutamine synthetase activity [36,37]. PDF2.5 has been reported to mediate Cd accumulation and tolerance by promoting cytoplasmic $\mathrm{Cd}$ efflux via chelation, thereby enhancing $\mathrm{Cd}$ detoxification and apoplastic accumulation. PDF2.6 functions in the chelation of $\mathrm{Cd}$ in A. thaliana $[38,39]$. The PDF family may play a key role in environmental acclimation improvement. We speculated that PDF1.5 acts as a signal molecule to regulate the expression levels of nitrate and cadmium-related transporters and regulate the adaptability of plants to low nitrogen and cadmium stress.

We have previously elucidated the mechanisms whereby LN enhances nitrogen-use efficiency and characterized plant responses to Cd stress [39,40]. Ethylene (ET) and jasmonic acid (JA) are two major plant stress hormones, also known as stress hormones [41]. Their synthesis is induced by stress, which regulates a series of stress responses in plants. Previous studies have shown that NRT1.5 and NRT1.8-mediated nitrate redistribution under stress conditions is regulated by ethylene/jasmonic acid (ET/JA) signals [8]. However, we were unable to identify any common mechanisms with respect to plant responses to environmental adaptation, especially for LN levels and the presence of Cd. Previous results showed that the expression of AtPDF1.5 was involved with LN and Cd stress (Figure S1). In addition, as a PDF1 member, the function of AtPDF1.5 is still unclear. Therefore, in the present study, we aimed to elucidate the function of the AtPDF1.5 gene, from the AtPDF1 family, in the adaptation to LN levels and Cd stress.

\section{Results}

\subsection{AtPDF1.5 Enhances Adaptation to LN Levels and Cd Stress}

Relative to the CK treatment, we found that the mutant $p d f 1.5-1$ and loss of function material pdf1.5-2 had lower total biomass while the overexpression lines (OE-1 and OE-2) had higher total biomass in the LN and Cd treatments (Figure 1a,b). When Col-0 plants were grown under LN conditions, the expression of AtPDF1.5 was upregulated in both shoots and roots (Figure S1a,c), whereas in plants treated with Cd, AtPDF1.5 was highly upregulated in roots, but not significantly in shoots (Figure S1b,d). 
a

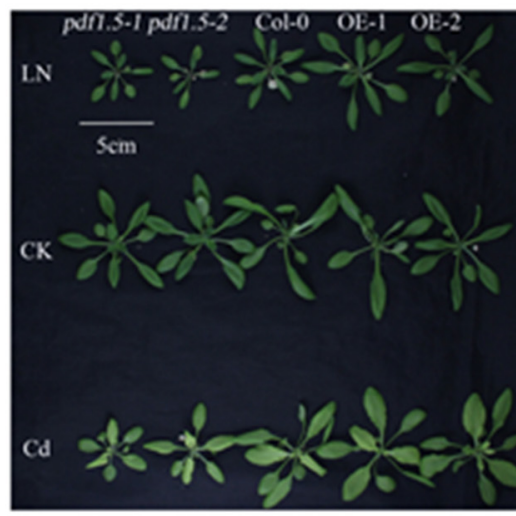

b

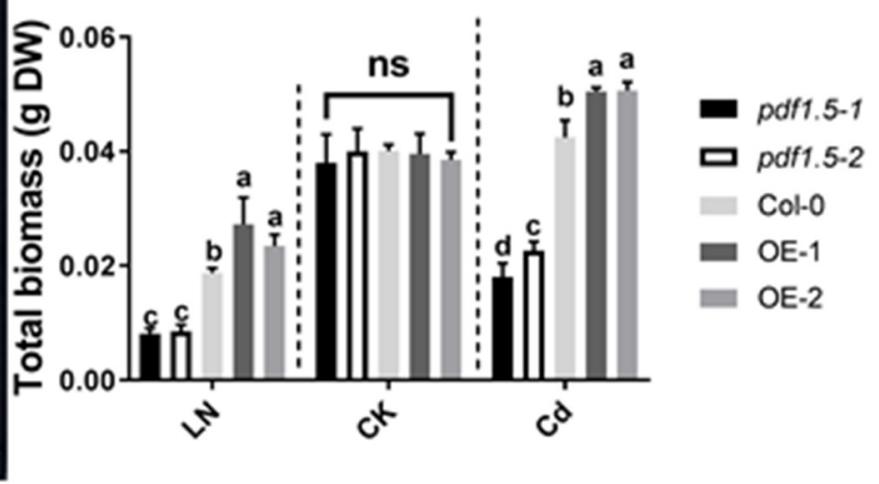

Figure 1. The phenotype for materials grown in low nitrogen (LN), control treatment (CK), or cadmium (Cd) conditions. (a) Phenotype for different materials-materials were harvested from 3-week-old hydroponically grown plants in either LN or Cd or CK conditions. (b) Total biomass for different materials. Bar height represents mean and error bars indicate standard deviation. Different letters on bars indicate significant differences based on Tukey's HSD $(p<0.05)$. Six replicates were used for measurements.

\subsection{AtPDF1.5 Influences Nitrogen Uptake and Translocation under LN Conditions}

Material verification for AtPDF1.5 is shown in Figure S2. In the LN treatment, wildtype Col-0 and pdf1.5 mutant seedlings showed no significant differences with respect to total nitrogen and shoot/root total nitrogen ratio (Figure $2 \mathrm{a}, \mathrm{b}$ ). Furthermore, relative to the wild-type Col-0, the AtPDF1.5 overexpressing plants (OE-1 and OE-2) had a higher total $\mathrm{N}$ and shoot/root total nitrogen ratio (Figure $2 \mathrm{a}, \mathrm{b}$ ). Under the $\mathrm{CK}$ conditions, relative to the wild-type Col-0 seedlings, we detected no significant differences in total biomass (Figure 1a), total nitrogen (Figure 2a), or the shoot/root total nitrogen ratio (Figure 2b), in either $p d f 1.5$ or OE-1 and OE-2.

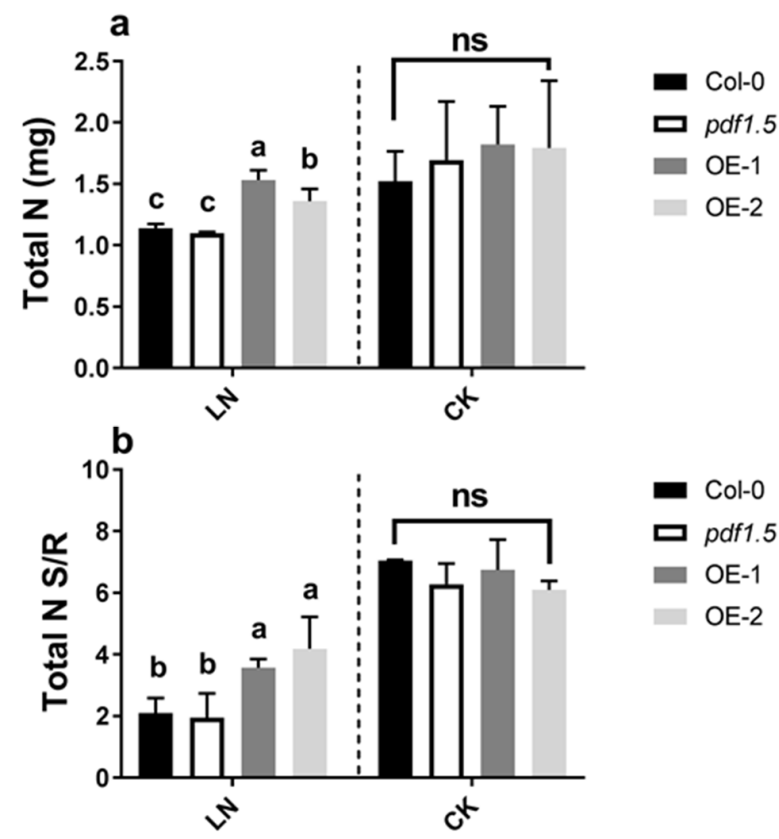

Figure 2. The involvement of AtPDF1.5 in the nitrogen uptake and distribution in low nitrogen (LN) conditions. (a) Total nitrogen (N). (b) Total nitrogen (N) shoot/root. Six replicates were used for measurements. Bar height represents mean and error bars indicate standard deviation. Different letters on bars indicate significant differences based on Tukey's HSD $(p<0.05)$. The statistical analysis was performed on different treatment genotypes. Six replicates were used for measurements. 
Our analysis of $\mathrm{NO}_{3}{ }^{-}$distribution under $\mathrm{LN}$ conditions revealed that, relative to the wild-type Col-0, pdf1.5, OE-1, and OE-2 seedlings all had higher shoot $\mathrm{NO}_{3}{ }^{-}$contents, whereas OE-1 and OE-2 had lower root $\mathrm{NO}_{3}{ }^{-}$contents (Figure 3a). Under $\mathrm{CK}$ conditions, the $p d f 1.5$ mutant had a higher root $\mathrm{NO}_{3}{ }^{-}$content than the wild-type Col-0 (Figure 3b). Regarding the shoot/root total $\mathrm{NO}_{3}{ }^{-}$ratio, relative to the wild-type Col-0 under LN conditions, the ratio for OE-1 and OE-2 plants was significantly higher, whereas for $p d f 1.5$, the ratio was significantly lower under LN conditions (Figure 3c). With regard to AtNRT1.5 expression, we found that under LN conditions, compared with wild-type Col-0, pdf1.5 mutant seedlings were characterized by a lower expression, whereas OE- 1 and OE-2 plants showed a higher expression (Figure 3d). In contrast, under LN conditions, the $p d f 1.5$ mutant showed higher AtNRT1.8 expression than the wild-type Col-0 (Figure 3e).

a

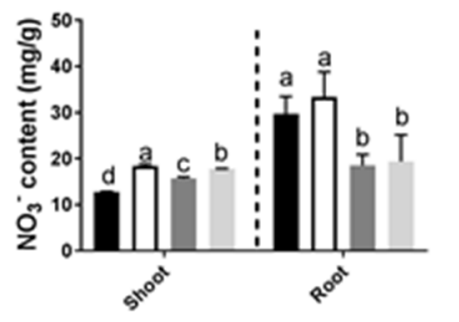

LN
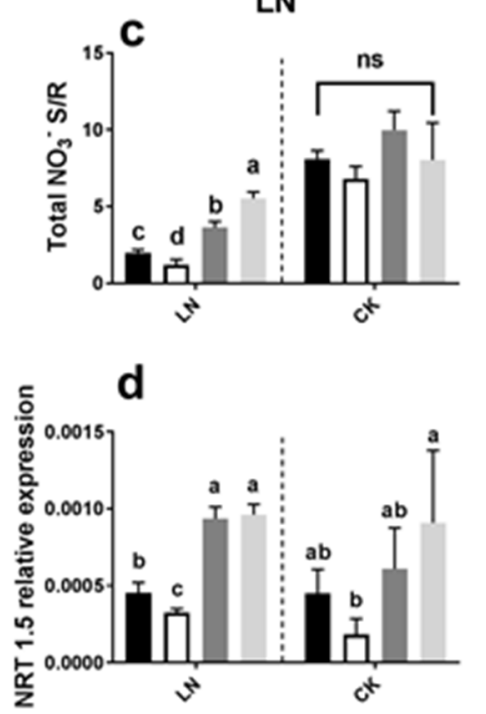

b

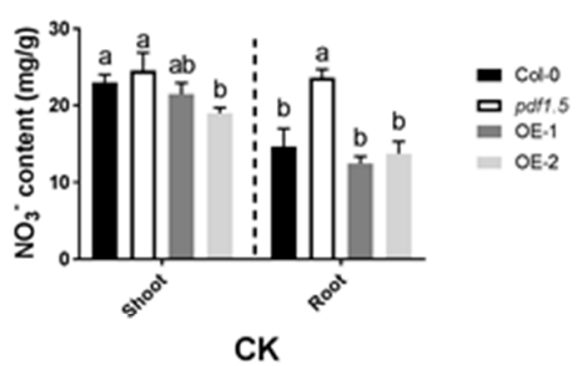

CK
= Col-0
D pdf1.5
$=$ OE-1
OE-2

- Col-0
D pdr1.5
$=$ OE-1
$=$ OE-2

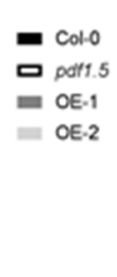

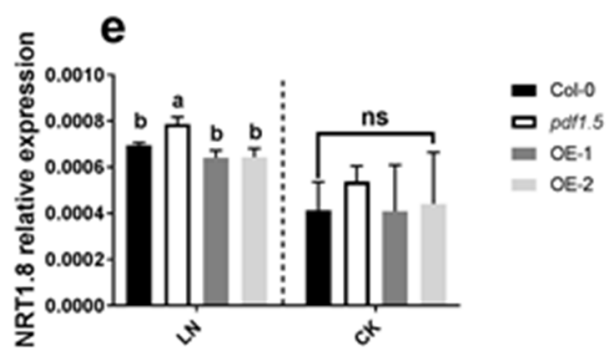

Figure 3. The involvement of AtPDF1.5 in $\mathrm{NO}_{3}{ }^{-}$distribution in low nitrogen (LN) conditions. (a) $\mathrm{NO}_{3}{ }^{-}$content for different materials grown in $\mathrm{LN}$ conditions. (b) $\mathrm{NO}_{3}{ }^{-}$content for different materials grown in $\mathrm{CK}$ conditions. (c) Total $\mathrm{NO}_{3}{ }^{-}$shoot/root rate for different materials grown in CK or LN conditions. (d) AtNRT1.5 relative expression for different materials grown in CK or LN conditions. (e) AtNRT1.8 relative expression for different materials grown in CK or LN conditions. Bar height represents mean and error bars indicate standard deviation. Different letters on bars indicate significant differences based on Tukey's HSD $(p<0.05)$. The statistical analysis was performed on different treatment genotypes. Six replicates were used for measurements.

\subsection{AtPDF1.5 Enhances Cd Tolerance and Accumulation in A. thaliana}

Based on phenotype, we found that under CK conditions, there were no significant differences in total biomass between either pdf1.5 or the OE- 1 and OE-2 seedlings and those of the wild-type Col-0. In contrast, in seedlings treated with $\mathrm{Cd}$, total biomass was lower in pdf1.5 and significantly higher in OE-1 and OE-2 (Figure 1a,b). Subsequent studies examining plant tolerance to $\mathrm{Cd}$ revealed that, compared with the wild-type Col- $0, p d f 1.5$ seedlings had a lower total $\mathrm{Cd}$, shoot $\mathrm{Cd}$ content, shoot/root total $\mathrm{Cd}$ ratio, and xylem 
sap volume (Figure $4 \mathrm{a}-\mathrm{d}$ ), but a higher root Cd content (Figure $4 \mathrm{~b}$ ). OE-1 and OE-2 had a higher total $\mathrm{Cd}$ and shoot $\mathrm{Cd}$ content than the wild-type Col-0 (Figure $4 \mathrm{a}, \mathrm{b}$ ). Subsequent analysis of the cationic contents of the xylem sap revealed that AtPDF1.5 might be involved in $\mathrm{Cd}$ allocation and influence $\mathrm{Ca}, \mathrm{K}$, and $\mathrm{Mn}$ distribution (Figure $4 \mathrm{e}$ ).
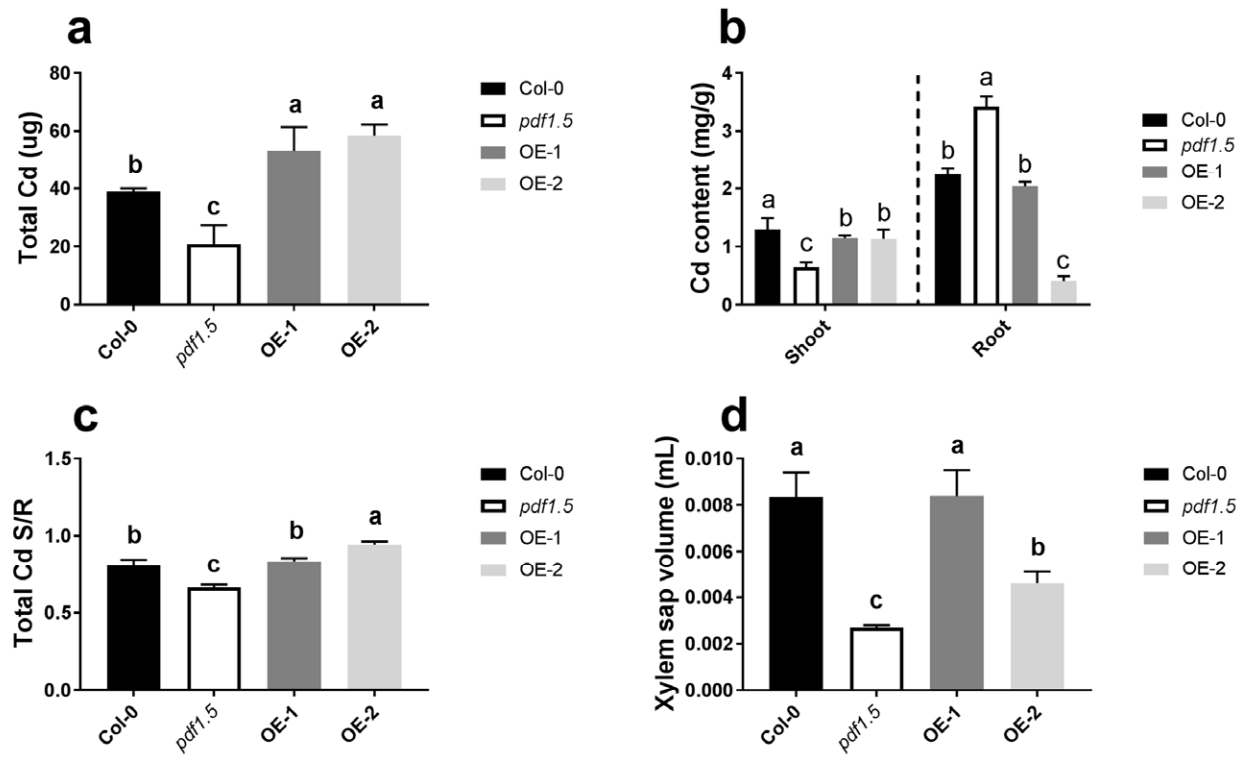

e

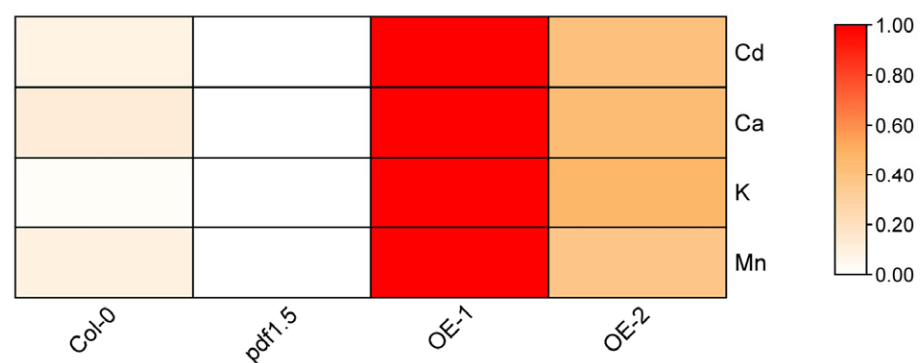

Figure 4. The involvement of AtPDF1.5 in cadmium (Cd) accumulation and distribution. (a) Total $\mathrm{Cd}$ for different materials grown in $\mathrm{Cd}$ conditions. (b) $\mathrm{Cd}$ content for different materials grown in Cd conditions. (c) Total Cd shoot/root rate for different materials grown in Cd conditions. (d) Xylem sap volume for different materials grown in Cd conditions. (e) Total Cd, Ca, K and Mn for different materials grown in Cd conditions. Data were normalized with zero-to-one method. Bar height represents mean and error bars indicate standard deviation. Different letters on bars indicate significant differences based on Tukey's HSD $(p<0.05)$. The statistical analysis was performed on different treatment genotypes. Six replicates were used for measurements.

\subsection{AtPDF1.5 Expression and Subcellular Localization}

To determine the mechanisms underlying the observed differences in element distribution, we examined the expression and subcellular localization of AtPDF1.5. A high expression of AtPDF1.5 was detected predominantly in the roots, stems, and leaves (Figure 5a). Subsequent GUS expression analysis indicated that AtPDF1.5 was highly expressed in nodes and the carpopodium (Figure $5 b, c$ ). To determine the subcellular localization of AtPDF1.5, we used 35S::AtPDF1.5-mRFP transgenic plants and 30\% sucrose solution to isolate the root cells from the plasma wall. Confocal microscopy revealed that AtPDF1.5 is located in the cell wall and cytoplasm (Figure 6). 
$\mathbf{a}$

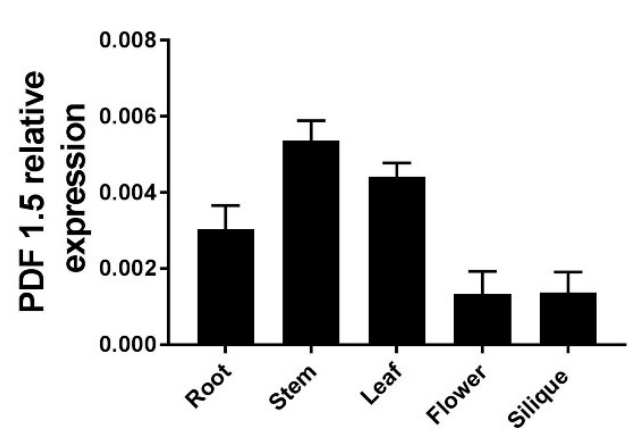

C

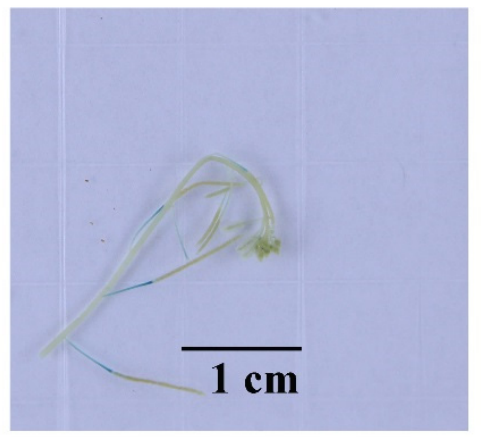

b

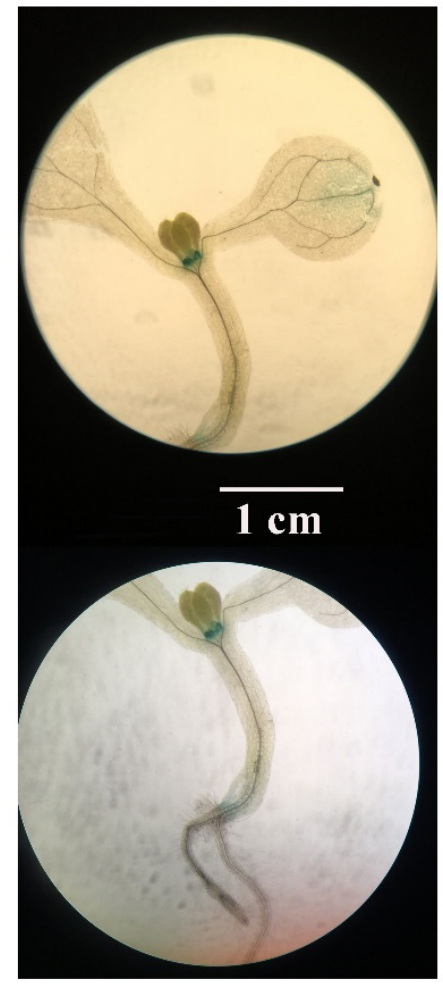

Figure 5. Expression pattern of AtPDF1.5. (a) Analysis of the relative expression level of AtPDF1.5 in the different $A$. thaliana tissues by quantitative PCR (qPCR). Tissues were harvested from 4 -week-old hydroponically grown plants (roots, stems, leaves, flowers, and siliques). Actin was used as the internal control. (b,c) Histochemical localization of $\beta$-glucuronidase (GUS) activity in transgenic plants expressing the GUS reporter gene under the control of the proAtPDF1.5 promoter. Bar height represents mean and error bars indicate standard deviation. The statistical analysis was performed on different treatment genotypes. Six replicates were used for measurements.

\subsection{AtPDF1.5 Is Involved in the Allocation of Multiple Metals in A. thaliana}

We analyzed the levels of different cations under CK, LN, and Cd conditions at both the seedling and pod stages. We used different plant cationic contents divided by Col-0 and used these values to generate heat maps (Figure 7). At the seedling stage, relative to the wild-type Col-0 under the CK condition, AtPDF1.5 contributed to a higher distribution of Fe in shoots (Figure 7a), whereas under LN conditions, AtPDF1.5 contributed to a higher accumulation of $\mathrm{Fe}, \mathrm{Mn}$, and $\mathrm{Cu}$ in roots (Figure $7 \mathrm{a}-\mathrm{c}$ ). Under $\mathrm{Cd}$ conditions, AtPDF1.5 was associated with higher $\mathrm{Mn}$ and $\mathrm{Cu}$ accumulations in roots (Figure 7b,c).

At the pod stage, relative to the wild-type Col-0 under CK conditions, AtPDF1.5 contributed to higher Fe levels in roots (Figure 7g), higher Mn levels in leaves (Figure 7h), and lower $\mathrm{Cu}$ levels in stems (Figure 7i). Under LN conditions, AtPDF1.5 contributed to higher $\mathrm{Fe}, \mathrm{Mn}$, and $\mathrm{Cu}$ levels in roots (Figure $7 \mathrm{~d}-\mathrm{f}$ ). In contrast, under $\mathrm{Cd}$ conditions, AtPDF1.5 contributed to lower Fe and Mn levels in siliques (Figure 7j,k), but higher Mn levels in leaves (Figure 7k). 


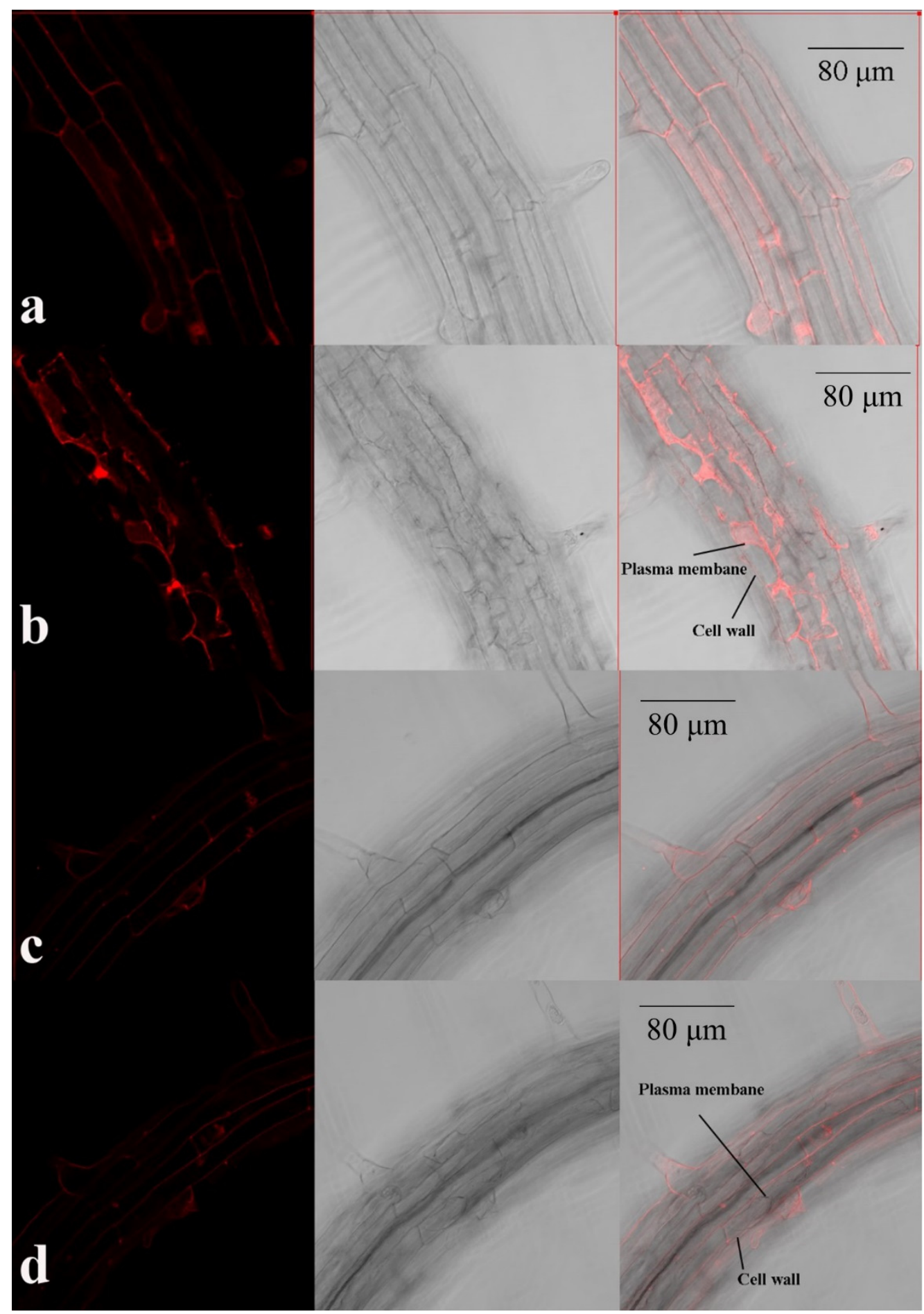

Figure 6. Subcellular localization of AtPDF1.5 in roots. (a) 35S::mRFP before sucrose treatment. (b) 35S::mRFP after sucrose treatment. (c) 35S::AtPDF1.5-mRFP before sucrose treatment. (d) 35S::AtPDF1.5-mRFP after sucrose treatment.

To determine the mechanisms underlying the observed differences in metal distribution, we examined the expression of selected metal transporter genes (AtHMP07, AtNRAMP4, AtNRAMP1, and AtHIPP3) in Arabidopsis seedlings subjected to the CK, LN, and $\mathrm{Cd}$ treatments (Figure 8 ). We found that, relative to the wild-type Col-0, there were no significant differences in the expression of these genes in pdf1.5, OE-1, or OE-2 seedlings, whereas under LN conditions, the expression of AtHMP07 was significantly higher in 
OE-1 and OE-2 seedlings, AtNRAMP4 was expressed in pdf1.5, and a high expression of AtHIPP3 was detected in pdf1.5. Under Cd conditions, compared with the wild-type Col-0, AtHMP07, AtNRAMP4, AtNRAMP1, and AtHIPP3 were highly expressed in OE-1 and OE-2 seedlings, whereas AtHMP07, AtNRAMP4, and AtHIPP3 expression levels were downregulated in the $p d f 1.5$ mutant (Figure 8).

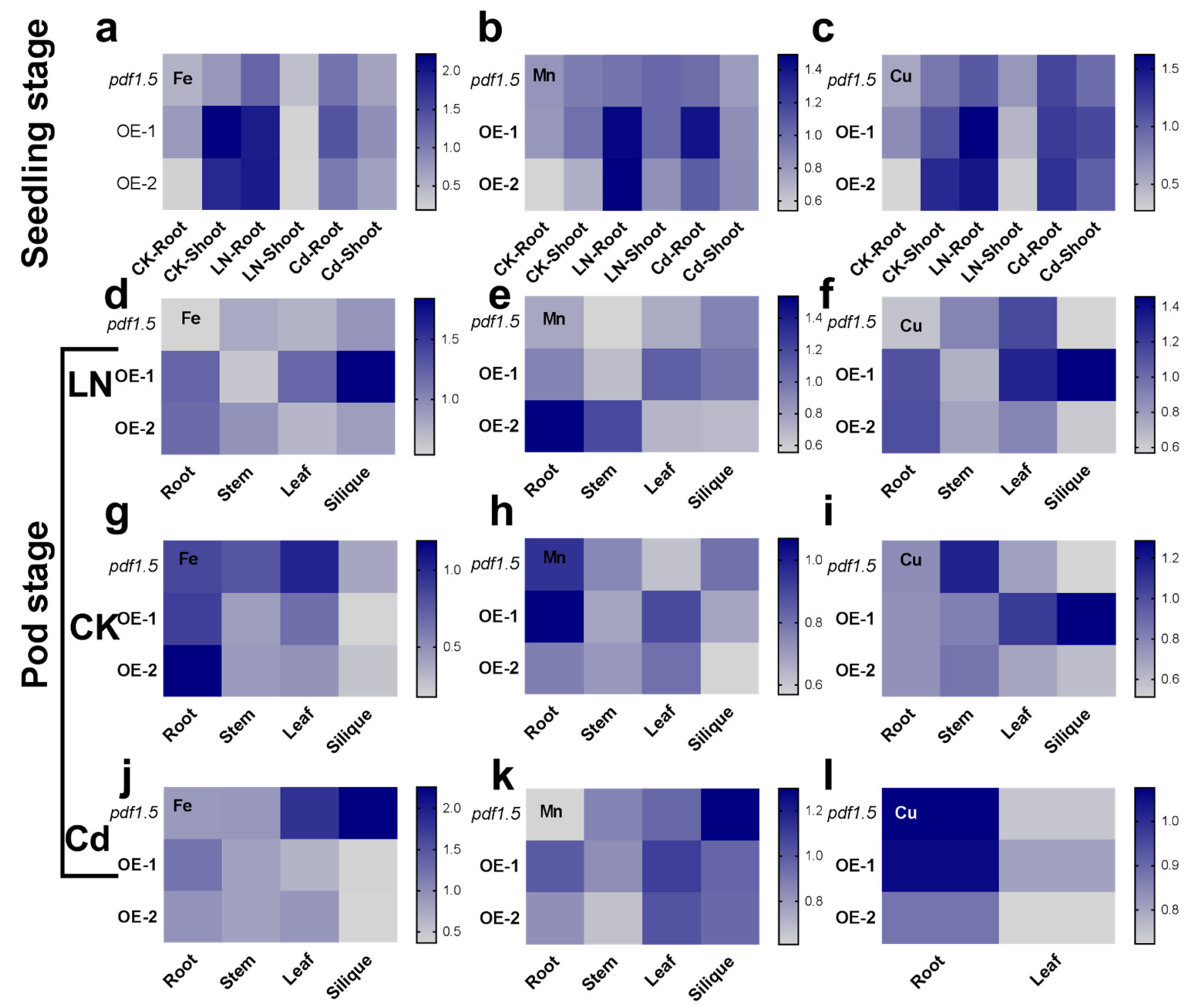

Figure 7. The involvement of AtPDF1.5 in Fe, Mn, and Cu distributions in the control treatment (CK), low nitrogen (LN), or cadmium (Cd) conditions. (a,d,g,j) Fe content for seedling and pod stage in CK or LN or Cd conditions. (b,e,h,k) Mn content for seedling and pod stage in CK or LN or Cd conditions. $(\mathbf{c}, \mathbf{f}, \mathbf{i}, \mathbf{l}) \mathrm{Cu}$ content for seedling and pod stage in CK or LN or Cd conditions. Different cationic content was divided by Col-0 relatively. Six replicates were used for measurements. 

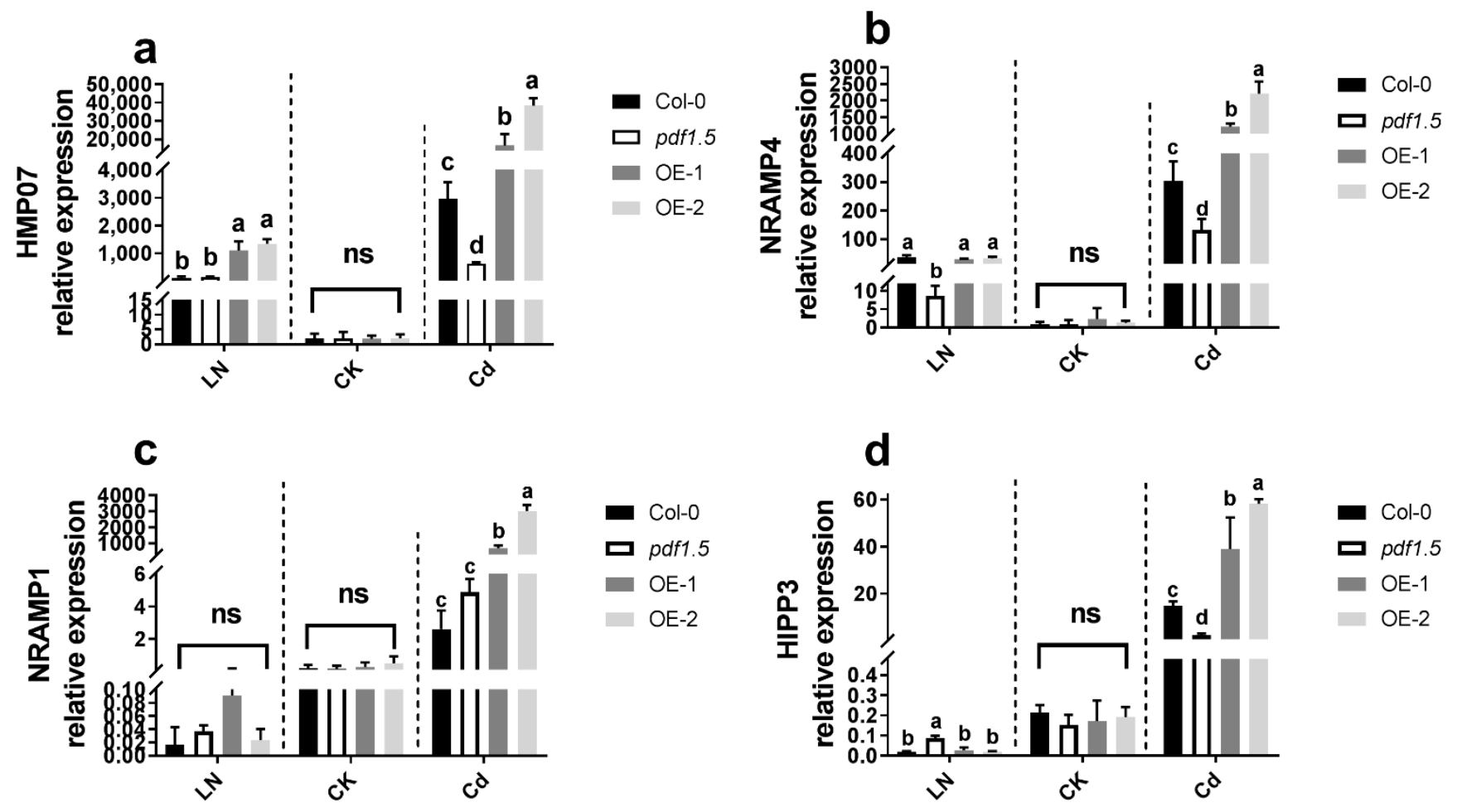

Figure 8. AtPDF1.5 involved the gene's expression for metal transporter. (a) AtHMP07 relative expression for different materials grown in LN or CK or Cd conditions. (b) AtNRAMP4 relative expression for different materials grown in LN or CK or Cd conditions. (c) AtNRAMP1 relative expression for different materials grown in LN or CK or Cd conditions. (d) AtHIPP3 relative expression for different materials grown in $\mathrm{LN}$ or $\mathrm{CK}$ or $\mathrm{Cd}$ conditions. Bar height represents mean and error bars indicate standard deviation. Different letters on bars indicate significant differences based on Tukey's HSD $(p<0.05)$. The statistical analysis was performed on different treatment genotypes. Six replicates were used for measurements.

\section{Discussion}

Previous studies on AtPDF1 have focused primarily on their roles in $\mathrm{Zn}$ tolerance and disease resistance [33]. For example, AtPDF1.2 has been shown to be induced by the coordinated interaction of the jasmonic acid and ethylene signaling pathways, which may function to induce defense-related gene expression in A. thaliana [42,43]. However, there is currently relatively limited information available regarding the role of AtPDF1 genes in LN tolerance and Cd resistance [37,44], particularly concerning the similarity of the underlying mechanisms.

In the present study, based on the analyses of the pdf1.5 mutant line and loss of function material ( $p d f 1.5-1$ and $p d f 1.5-2)$, two AtPDF1.5 overexpression lines (OE-1 and OE-2), and the wild-type Col-0 (Figure 1), we found that the expression of AtPDF1.5 was upregulated in response to both the $\mathrm{LN}$ and $\mathrm{Cd}$ treatments, particularly the latter, in which there was a 61-fold increase in root expression (Figure S1).

\subsection{AtPDF1.5 Enhances Adaptation to LN by Regulating AtNRT1.5 and AtNRT1.8 Expression}

Considering that the major function of AtPDF1.5 appears to be nutrient element distribution, and compared with $\mathrm{CK}$, the root system architecture was significantly changed in $\mathrm{LN}$ or Cd conditions, but the shoot/root ratio was not significantly different (Figure S3). Therefore, we did not examine nitrogen uptake further (Figure 5). AtPDF1.5 is a small peptide, and it has been previously reported that small peptides can affect transporters through their downstream receptors and long-distance signals by binding to receptors [45-47]. Therefore, we hypothesized that AtPDF1.5 might regulate transporters' expression through these two ways. 
With respect to nitrogen distribution [48], we found that $A t P D F 1.5$ is involved in $\mathrm{NO}_{3}{ }^{-}$ distribution under LN conditions but not under CK conditions (Figure $3 \mathrm{a}-\mathrm{c}$ ). To determine the mechanisms underlying this activity, we examined the expression of AtNRT1.5 and AtNRT1.8 under both LN and CK conditions [48,49]. Concerning AtNRT1.5 in response to LN [46], we observed that, relative to the wild-type Col-0, AtNRT1.5 was upregulated in the overexpression lines OE-1 and OE-2 and downregulated in the pdf1.5 mutant (pdf1.5-1), whereas under CK conditions, the expression of AtNRT1.5 in pdf1.5 seedlings did not differ significantly from that in wild-type Col-0 [8]. Contrastingly, we found that under LN conditions, the expression of AtNRT1.8 in pdf1.5 was upregulated, relative to that in the wild-type Col-0 and the two overexpression lines $[9,49]$. However, no significant differences were detected under CK conditions. These observations indicate that AtPDF1.5 may enhance the acclimation of Arabidopsis to LN by involving the expression of AtNRT1.5 and AtNRT1.8 (Figure 3d,e).

\subsection{AtPDF1.5 Enhances Cd Tolerance by Increasing Cd Transport to Shoots}

We found that under the CK treatment, there were no significant differences among the wild-type Col-0, pdf1.5, OE-1, and OE-2 seedlings with respect to phenotype (Figure 1a,b). However, in the vegetative growth period when exposed to $\mathrm{Cd}$, the mutant seedlings had a lower total biomass than the wild-type Col-0 seedlings, whereas the overexpression lines OE-1 and OE-2 had a higher total biomass (Figure 1a,b). Furthermore, relative to the wild-type Col-0 seedlings, the $p d f 1.5$ mutant had a lower $\mathrm{Cd}$ accumulation, whereas OE-1 and $\mathrm{OE}-2$ had a higher $\mathrm{Cd}$ accumulation (Figure $4 \mathrm{a}$ ). These observations are consistent with the findings previously reported for AtPDF2.5 [39]. We also obtained lower values for the $\mathrm{Cd}$ content, shoot/root total $\mathrm{Cd}$ ratio, xylem sap volume, and metal content in xylem sap in the pdf1.5 mutant (Figure 4b-e). Collectively, these observations indicate that AtPDF1.5 may enhance $\mathrm{Cd}$ transport to shoots, as indicated by the respective $\mathrm{Cd}$ contents of the shoots and roots (Figure $4 \mathrm{~b}$ ). We suspect AtPDF1.5 could promote the chelation efficient of $\mathrm{Cd}$, and the low shoot/root total $\mathrm{Cd}$ ratio may protect the nutrient absorption of roots more effectively. Our results showed that the transport of Cd was not enhanced; meanwhile, the overexpression resulted in an increase in total $\mathrm{Cd}$ and a decrease in aboveground content due to the increase in biomass. PDF1.5 is localized to the cell wall and may play a role in detoxifying cadmium by chelating cadmium to the cell wall. Consequently, our findings indicate that AtPDF1.5 enhances Cd tolerance by regulating the transport of this metal $[11,50,51]$.

\subsection{AtPDF1.5 Enhances Cd Transport and Affects the Transport of Other Cations}

Our analysis of the $\mathrm{Cd}, \mathrm{K}, \mathrm{Ca}$, and Mn levels in xylem sap indicates that AtPDF1.5 may mediate the distribution of $\mathrm{Cd}$ and influence the transport of other cations (Figures 4e and 7) [52]. Therefore, we examined the levels of cations in various tissues and at different growth stages [53,54]. We found that AtPDF1.5 is involved in Cd allocation and plays a role in determining the distribution of other cations (Figure 7).

To assess the associated regulatory mechanisms, we examined the expression of selected metal transport genes $[28,29,55]$. Under CK conditions, we detected no significant differences in the expression of AtHMP07, AtNRAMP4, AtNRAMP1, and AtHIPP3 in the $p d f 1.5$ mutant and overexpression lines and the wild-type Col-0. However, in response to LN treatment, AtHMP07 was upregulated in the OE-1 and OE-2 overexpression lines (Figure 8a), AtNRAMP4 was downregulated in the pdf1.5 mutant (Figure 8b) [25-27], and AtHIPP3 was upregulated in the pdf1.5 mutant (Figure 8d) [31]. Moreover, in seedlings treated with Cd, relative to the wild-type Col-0, the expression of AtHMP07, AtNRAMP4, and AtHIPP3 was downregulated in the pdf1.5 mutant and upregulated in the overexpression lines (Figure $8 \mathrm{a}, \mathrm{b}, \mathrm{d}$ ), and AtNRAMP1 was also characterized by the upregulated expression of overexpression lines (Figure $8 \mathrm{c}$ ).

Based on these observations, we speculate that AtPDF1.5 enhances plant adaptation to $\mathrm{LN}$ conditions and the presence of $\mathrm{Cd}$ by modifying the distribution of nutrient ele- 
ments [56,57]. As a small molecular protein [44,58-60], we speculate that AtPDF1.5 may be involved in the processing or transmission of signal substances and play an important role in the remediation of $\mathrm{Cd}$ pollution and LN acclimation. As a key member of the AtPDF1 family [32,61], AtPDF1.5 warrants further research, as it may have other essential functions in environmental acclimation. We have studied the root expression of AtPDF1.5 in Brassica napus under CK and LN conditions and obtained the same results (Figure S4). There is a need for the time-dependent application of omics technologies to compare various $p d f 1.5$ mutants and dissect the order of events.

\section{Materials and Methods}

\subsection{Materials and Growth Conditions}

Seeds of wild-type $A$. thaliana ecotype Col-0 were obtained from the Shanghai Institute of Plant Physiology and Ecology. AtPDF1.5 (AT1G55010) knockout mutant pdf1.5-1 (SALK_151733) and loss of function material pdf1.5-2 (SALK_070545) were acquired from the Eurasian A. thaliana Stock Centre (uNASC; http://arabidopsis.info/, 29 December 2019). After validation, we renamed knockout mutant $p d f 1.5-1$ (SALK_151733) to " $p d f 1.5$ " for the next study.

We generated the AtPDF1.5 overexpression lines OE-1 and OE-2. The seeds of Col-0, pdf1.5 mutant, loss of function material, and AtPDF1.5 overexpression lines were germinated and grown in a greenhouse $\left(300 \mu \mathrm{mol}\right.$ photons $\mathrm{m}^{-2} \mathrm{~s}^{-1}, 16 \mathrm{~h}$ photoperiod, $\left.22{ }^{\circ} \mathrm{C}\right)$ for $10 \mathrm{~d}$. At the two-leaf growth stage, each seedling was transferred to a 5-L pot, and the pots were given different treatments. For the CK treatment (control conditions), the seedlings were provided with a nutrient solution containing $1.25 \mathrm{mM} \mathrm{KNO}_{3}, 0.625 \mathrm{mM} \mathrm{KH}_{2} \mathrm{PO}_{4}$, $1.25 \mu \mathrm{M}$ Fe-EDTA, $0.5 \mathrm{mM} \mathrm{MgSO}_{4}, 0.5 \mathrm{mM} \mathrm{Ca}\left(\mathrm{NO}_{3}\right)_{2}, 0.05 \mu \mathrm{M} \mathrm{NaMoO}_{4}, 0.125 \mu \mathrm{M} \mathrm{CuSO}_{4}$, $0.25 \mu \mathrm{M} \mathrm{ZnSO}_{4}, 3.5 \mu \mathrm{M} \mathrm{MnCl}_{2}$, and $17.5 \mu \mathrm{M} \mathrm{H}_{3} \mathrm{BO}_{3}$. For the $\mathrm{LN}$ treatment, plants were provided with a nutrient solution containing $0.15 \mathrm{mM} \mathrm{KNO}_{3}$ and $0 \mathrm{mM} \mathrm{Ca}\left(\mathrm{NO}_{3}\right)_{2}$, and $\mathrm{K}$ and $\mathrm{Ca}$ were supplied as $\mathrm{KCl}$ and $\mathrm{CaCl}_{2}$, respectively [48]. Other components were the same as those used in the $\mathrm{CK}$ treatment. For the $\mathrm{Cd}(10 \mu \mathrm{M} \mathrm{CdCl})$ treatment, all plants were grown in the CK nutrient solution for the initial $14 \mathrm{~d}$ and thereafter grown for a further $7 \mathrm{~d}$ with $10 \mu \mathrm{M} \mathrm{CdCl}_{2}$ supplementation. The $\mathrm{pH}$ of the medium was adjusted to 5.8, and the medium was renewed at $4 \mathrm{~d}$ intervals [37]. Six replicates were used for all measurements.

\subsection{Preparation of DNA Constructs and Plant Transformation}

We initially used polymerase chain reaction (PCR) to amplify a 580 bp genomic fragment immediately upstream of the AtPDF1.5 start codon, using the ProAtPDF1.5 primer pair F: CGACGGCCAGTGCCAAGCTTGTGTGATTAATGTTATGTGT and R: GACTGACCACCCGGGGATCCATGACTTACTACTTAGATTT. The amplified promoter fragment was then sub-cloned into a pCAMBIA1300-GUS binary vector [39]. Constructs were transferred into A. thaliana using the floral dip method [62]. Transgenic plants were selected using hygromycin $B$ and confirmed by sequencing. To determine the subcellular localization of AtPDF1.5 in A. thaliana, the 35S::mRFP fragment was recovered from 35S::mRFP/PA7 via HindIII/SacI restriction digestion and the resulting 35S::mRFP fragment was inserted into pCAMBIA1300 to generate the 35S::mRFP/pCAMBIA1300 construct. The coding sequence of AtPDF1.5 was PCR amplified using the AtPDF1.5 primer pair F: CGGGGGACTCTAGAGGATCCTGGCTAAGTTTTGTACCACC and R: TCGGAGGAGGCCATACTAGTACCAGCGCAATATCCATCAT, and the amplified AtPDF1.5 coding sequence fragment was sub-cloned into the binary vector 35S::mRFP/pCAMBIA1300 to generate the construct 35S::AtPDF1.5 -mRFP/pCAMBIA1300, as described by Luo et al. [39,44]. Six replicates were used for measurements.

\subsection{Expression, $\beta$-Glucuronidase (GUS) Histochemical Analyses, and Subcellular Localization}

Total RNA was extracted from the collected tissues (root, stem leaf, flower, silique, and seedling) using TRIZOL reagent according to the manufacturer's instructions (Invitrogen, 
Carlsbad, CA, USA). Complementary DNAs were synthesized using a PrimeScript ${ }^{\mathrm{TM}}$ RT Kit with gDNA Eraser (Perfect Real Time; TAKARA, Shanghai, China) following the manufacturer's protocol. The relative expression levels of target genes were determined by reverse transcription quantitative PCR (RT-qPCR) performed using an Applied Biosystems StepOne ${ }^{\mathrm{TM}}$ Real-Time PCR System with SYBR Premix Ex-Taq (TAKARA), according to the manufacturer's instructions. The relative expression of detected genes was normalized to that of the reference gene using the delta-delta $\mathrm{Ct}$ (threshold cycle, $\Delta \Delta \mathrm{Ct}$ ) method. The primers used in this study are listed in Table S1, and the expression level of AtPDF1.5 was normalized to that of Actin. Histochemical staining, driven by the ProAtPDF1.5 promoter, was performed using a GUS histochemical analysis kit (Real-Times Biotechnology Co., Ltd., Beijing, China). GUS staining patterns in root tissues were observed under an Olympus BX51 microscope and photographed using a Fujifilm X-A3 camera [39]. Six replicates were used for measurements.

To determine the subcellular localization of AtPDF1.5 in A. thaliana, the coding sequence of AtPDF1.5 was amplified by PCR using primers AtPDF1.5F and AtPDF1.5R (Supplementary Table S1) and then subcloned to generate the construct 35S::mRFP/1300. The resulting fragments were fused in-frame to the $5^{\prime}$ terminus of the monomer red fluorescent protein (mRFP) gene to generate the 35S::AtPDF1.5-mRFP/pCAMBIA1300 constructs. These constructs were modified by replacing the $35 \mathrm{~S}$ promoter with the native promoter proAtPDF1.5, resulting in the proAtPDF1.5::AtPDF1.5-mRFP/pCAMBIA1300 constructs, which were transformed into $A$. thaliana using the floral dip method [37]. Root tissues of the resulting transgenic lines were first subjected to mRFP imaging using confocal microscopy (LSM880; Zeiss) and then reimaged after being treated with 30\% sucrose.

\subsection{Nitrogen Concentration Assay}

The dry biomass and nitrogen concentration of treated plants were determined at the seedling stage ( $21 \mathrm{~d}$ after transplantation). Plants were harvested and oven-dried to constant weight by heating at $105^{\circ} \mathrm{C}$ for $30 \mathrm{~min}$, followed by a slow drying at $65^{\circ} \mathrm{C}$. Nitrogen concentrations were determined using the Kjeldahl method [63]. The entire tissues of dried plants were initially digested with $\mathrm{H}_{2} \mathrm{SO}_{4}$ and then subjected to analysis using a Foss Auto Analyzer Unit (AutoAnalyzer 3; SEAL Analytical, Inc., Nordsted, Germany). Six replicates were used for measurements. Physiological nitrogen-use efficiency was calculated using the following equation [40]:

Physiological nitrogen-use efficiency $=$ Plant total biomass $/$ Plant total nitrogen.

\subsection{Xylem Sap Collection and $\mathrm{NO}_{3}{ }^{-}$Concentration Assay}

We used the method of Wu to collect xylem sap [40]. Using 21-day-old plants, stems were cut $1 \mathrm{~cm}$ above the intact roots, which were left to grow in the respective nutrition solutions. Xylem saps were collected by $10 \mu \mathrm{L}$ pipettors and saved in pre-weighed $2 \mathrm{~mL}$ ep tubes. Tubes were placed on ice when the experiment started. After $45 \mathrm{~min}$, the volume of xylem collected was calculated as the weight gain of the ep tube. $\mathrm{NO}_{3}{ }^{-}$concentrations were determined using the aforementioned Foss Auto Analyzer Unit. Six replicates were used for measurements.

\subsection{Cation Concentration Assay}

Analysis of cation concentration was performed as described by Gong and Luo $[39,64]$. Dried samples of whole plants and xylem sap were initially digested with $70 \% \mathrm{HNO}_{3}$. The samples were washed with distilled water twice before drying. Cation concentrations in the resulting digests were determined using inductively coupled plasma mass spectrometry (ICP-MS: ELAN DRC-e; PerkinElmer, Norwalk, CT, USA). Six replicates were used for measurements. 


\title{
4.7. Statistical Analysis
}

Statistical analyses were performed using SPSS software (version 25.0; SPSS Statistics Inc., Chicago, IL, USA). All experiments were conducted using a completely randomized design. Data were compared by two-way ANOVA and Tukey's HSD post hoc test. Differences were considered significant at the $p<0.05$ level [65].

\section{Conclusions}

In the long-term process of breeding, people often focus on the breeding of high-yield varieties but ignore their resistance to environmental stress. Cultivars with good growth conditions have poor resistance to adversity, while cultivars with strong resistance to adversity have poor growth conditions. Deep understanding of the relationship between plant growth and stress resistance is of great significance for improving crop yield and resistance. Our study revealed the function of AtPDF1.5. As a short peptide of a small molecule, we suspect that AtPDF1.5 may play a key role in chelation and signal transmission; the mechanism for cadmium tolerance may be chelation, and for LN it may be signaling function, thus improving the adaptation for LN and Cd stress in plants. Our study provided a new insight for breeding high-yield and high-resistance crops, especially in phytoremediation for toxic metal-polluted areas. Based on our research, it is not difficult to explore the nutritional element-rich product in crop production.

Supplementary Materials: The following are available online at https:/ /www.mdpi.com/article/10 .3390/ijms221910455/s1, Figure S1: The AtPDF1.5 expression of Col-0 was induced by low nitrogen $(\mathrm{LN})$ and cadmium (Cd). Figure S2: Materials verification for AtPDF1.5. Figure S3: The root phenotype for materials grown in low nitrogen $(\mathrm{LN})$ or cadmium $(\mathrm{Cd})$ condition. Figure S4: BnPDF1.5 relative expression of root for two contrasting Brassica napus genotypes grown in the control treatment (CK) or low nitrogen (LN) condition. Table S1: Primers used in this study.

Author Contributions: Z.W. and Z.Z. designed the experiments. Z.W. performed most of the experiments. Z.W. and J.L. analyzed the data. Z.W., J.L. and Z.Z. wrote the manuscript. Data curation: D.L. Formal analysis: N.Y. Visualization: H.S. All authors have read and agreed to the published version of the manuscript.

Funding: This study was partly supported by the National Natural Science Foundation of China (31800202, 32072664); Province Key R\&D Program of Hunan (2018NK1010); the National Oilseed Rape Production Technology System of China; the Double First-Class Construction Project of Hunan Agricultural University (kxk201801005); and the Innovative Research Groups of the Natural Science Foundation of Hunan Province (2019JJ10003).

Conflicts of Interest: The authors declare no conflict of interest.

\author{
Abbreviations \\ CK: Control; GUS: $\beta$-glucuronidase; HIPP3: Heavy metal-associated isoprenylated \\ plant protein-3; LN: Low nitrogen; NRAMP1: Natural resistance-associated macrophage \\ protein-1; NRAMP4: Natural resistance-associated macrophage protein-4; NRT1.5: Nitrate \\ transporter 1.5; NRT1.8: Nitrate transporter 1.8; PDF: Plant defensin; Cd: Cadmium.
}

\section{References}

1. Mendez, E.; MORENO, A.; COLILlA, F.; PELAEZ, F.; LIMAS, G.G.; MENDEZ, R.; SORIANO, F.; SALINAS, M.; de HARO, C. Primary structure and inhibition of protein synthesis in eukaryotic cell-free system of a novel thionin, $\gamma$-hordothionin, from barley endosperm. Eur. J. Biochem. 1990, 194, 533-539. [CrossRef]

2. Larsen, B.; Xu, D.; Halkier, B.A.; Nour-Eldin, H.H. Advances in methods for identification and characterization of plant transporter function. J. Exp. Bot. 2017, 68, 4045-4056. [CrossRef]

3. Wang, J.; Dun, X.; Shi, J.; Wang, X.; Liu, G.; Wang, H. Genetic Dissection of Root Morphological Traits Related to Nitrogen Use Efficiency in Brassica napus L. under Two Contrasting Nitrogen Conditions. Front. Plant Sci. 2017, 8. [CrossRef] [PubMed]

4. ANDREWS, M. The partitioning of nitrate assimilation between root and shoot of higher plants. Plant. Cell Environ. 1986, 9, 511-519. [CrossRef] 
5. Han, Y.-L.; Song, H.-X.; Liao, Q.; Yu, Y.; Jian, S.-F.; Lepo, J.E.; Liu, Q.; Rong, X.-M.; Tian, C.; Zeng, J.; et al. Nitrogen use efficiency is mediated by vacuolar nitrate sequestration capacity in roots of Brassica napus. Plant Physiol. 2016, 170, 1684-1698. [CrossRef] [PubMed]

6. Wang, F.; Yu, G.; Liu, P. Transporter-mediated subcellular distribution in the metabolism and signaling of jasmonates. Front. Plant Sci. 2019, 10, 1-8. [CrossRef]

7. Tang, Z.; Fan, X.; Li, Q.; Feng, H.; Miller, A.J.; Shen, Q.; Xu, G. Knockdown of a rice stelar nitrate transporter alters long-distance translocation but not root influx. Plant Physiol. 2012, 160, 2052-2063. [CrossRef]

8. Lin, S.H.; Kuo, H.F.; Canivenc, G.; Lin, C.S.; Lepetit, M.; Hsu, P.K.; Tillard, P.; Lin, H.G.; Wang, Y.Y.; Tsai, C.B.; et al. Mutation of the Arabidopsis NRT1.5 nitrate transporter causes defective root-to-shoot nitrate transport. Plant Cell 2008, 20, 2514-2528. [CrossRef]

9. Li, J.-Y.; Fu, Y.-L.; Pike, S.M.; Bao, J.; Tian, W.; Zhang, Y.; Chen, C.-Z.; Zhang, Y.; Li, H.-M.; Huang, J.; et al. The Arabidopsis Nitrate Transporter NRT1.8 Functions in Nitrate Removal from the Xylem Sap and Mediates Cadmium Tolerance. Plant Cell Online 2010, 22, 1633-1646. [CrossRef]

10. Yang, S.; Gong, Z.; Guo, Y.; Gong, J. Studies on plant responses to environmental change in China: The past and the future. Sci. Sin. 2019, 49, 1457-1478. [CrossRef]

11. Zhang, W.W.; Meng, J.J.; Xing, J.Y.; Yang, S.; Guo, F.; Li, X.G.; Wan, S.B. The K+/H+ antiporter AhNHX1 improved tobacco tolerance to $\mathrm{NaCl}$ stress by enhancing $\mathrm{K}+$ retention. J. Plant Biol. 2017, 60, 259-267. [CrossRef]

12. Luo, Y.; Rimmer, D.L. Zinc-copper interaction affecting plant growth on a metal-contaminated soil. Environ. Pollut. 1995, 88, 79-83. [CrossRef]

13. Lepp, N.W. Effect of Heavy Metal Pollution on Plants: Effects of Trace Metals on Plant Function; Springer Science \& Business Media: Berlin, Germany, 2012; ISBN 9401173397.

14. Lu, L.; Tian, S.; Liao, H.; Zhang, J.; Yang, X.; Labavitch, J.M.; Chen, W. Analysis of metal element distributions in rice (Oryza sativa L.) seeds and relocation during germination based on X-ray fluorescence imaging of $\mathrm{Zn}, \mathrm{Fe}, \mathrm{K}, \mathrm{Ca}$, and Mn. PLoS ONE 2013, 8, e57360. [CrossRef]

15. Ramos, O.M.; Magnitskiy, S.; Darghan, A. Effect of nitrogen and potassium on plant height and stem diameter of Jatropha curcas L. in Colombian tropical dry forest. Agron. Colomb. 2019, 37, 203-212. [CrossRef]

16. Huber, D.M.; Arny, D.C. Interactions of potassium with plant disease. Potassium Agric. 1985, 467-488. [CrossRef]

17. Riveras, E.; Alvarez, J.M.; Vidal, E.A.; Oses, C.; Vega, A.; Gutiérrez, R.A. The calcium ion is a second messenger in the nitrate signaling pathway of Arabidopsis. Plant Physiol. 2015, 169, 1397-1404. [CrossRef]

18. McHargue, J.S. The role of manganese in plants. J. Am. Chem. Soc. 1922, 44, 1592-1598. [CrossRef]

19. ul Hassan, Z.; Ali, S.; Rizwan, M.; Ali, Q.; Haider, M.Z.; Adrees, M.; Hussain, A. Role of Iron in Alleviating Heavy Metal Stress. In Essential Plant Nutrients; Springer: Berlin, Germany, 2017; pp. 335-350.

20. Tsai, H.H.; Schmidt, W. Mobilization of iron by plant-borne coumarins. Trends Plant Sci. 2017, 22, 538-548. [CrossRef] [PubMed]

21. Nisha Kevat, N.; Sharma, P.K. Photosynthesis in copper mediated plant is affected due to oxidative damage caused by reactive oxygen species (ros) generation. Int. J. Recent Sci. Res. 2016, 7, 14009-14015.

22. Makowska, K.; Oleszczuk, S.; Zimny, J. The effect of copper on plant regeneration in barley microspore culture. Czech J. Genet. Plant Breed. 2017, 53, 17-22. [CrossRef]

23. Dupont, C.L.; Butcher, A.; Valas, R.E.; Bourne, P.E.; Caetano-Anollés, G. History of biological metal utilization inferred through phylogenomic analysis of protein structures. Proc. Natl. Acad. Sci. USA 2010, 107, 10567-10572. [CrossRef]

24. Huffman, D.L.; O'Halloran, T.V. Function, Structure, and Mechanism of Intracellular Copper Trafficking Proteins. Annu. Rev. Biochem. 2001, 70, 677-701. [CrossRef]

25. Zlobin, I.E.; Kholodova, V.P.; Rakhmankulova, Z.F.; Kuznetsov, V.V. Brassica napus responses to short-term excessive copper treatment with decrease of photosynthetic pigments, differential expression of heavy metal homeostasis genes including activation of gene NRAMP4 involved in photosystem II stabilization. Photosynth. Res. 2015, 125, 141-150. [CrossRef] [PubMed]

26. Oomen, R.J.F.J.; Wu, J.; Lelièvre, F.; Blanchet, S.; Richaud, P.; Barbier-Brygoo, H.; Aarts, M.G.M.; Thomine, S. Functional characterization of NRAMP3 and NRAMP4 from the metal hyperaccumulator Thlaspi caerulescens. New Phytol. 2009, 181, 637-650. [CrossRef] [PubMed]

27. Agorio, A.; Giraudat, J.; Bianchi, M.W.; Marion, J.; Espagne, C.; Castaings, L.; Lelièvre, F.; Curie, C.; Thomine, S.; Merlot, S. Phosphatidylinositol 3-phosphate-binding protein AtPH1 controls the localization of the metal transporter NRAMP1 in Arabidopsis. Proc. Natl. Acad. Sci. USA 2017, 114, E3354-E3363. [CrossRef] [PubMed]

28. Chen, H.M.; Wang, Y.M.; Yang, H.L.; Zeng, Q.Y.; Liu, Y.J. NRAMP1 promotes iron uptake at the late stage of iron deficiency in poplars. Tree Physiol. 2019, 39, 1235-1250. [CrossRef]

29. De Abreu-Neto, J.B.; Turchetto-Zolet, A.C.; De Oliveira, L.F.V.; Bodanese Zanettini, M.H.; Margis-Pinheiro, M. Heavy metalassociated isoprenylated plant protein (HIPP): Characterization of a family of proteins exclusive to plants. FEBS J. 2013, 280, 1604-1616. [CrossRef] [PubMed]

30. Sato, M.; Mitra, R.M.; Coller, J.; Wang, D.; Spivey, N.W.; Dewdney, J.; Denoux, C.; Glazebrook, J.; Katagiri, F. A high-performance, small-scale microarray for expression profiling of many samples in Arabidopsis-pathogen studies. Plant J. 2007, 49, 565-577. [CrossRef] 
31. Zschiesche, W.; Barth, O.; Daniel, K.; Böhme, S.; Rausche, J.; Humbeck, K. The zinc-binding nuclear protein HIPP3 acts as an upstream regulator of the salicylate-dependent plant immunity pathway and of flowering time in Arabidopsis thaliana. New Phytol. 2015, 207, 1084-1096. [CrossRef]

32. Shahzad, Z.; Ranwez, V.; Fizames, C.; Marquès, L.; Le Martret, B.; Alassimone, J.; Godé, C.; Lacombe, E.; Castillo, T.; SaumitouLaprade, P.; et al. Plant Defensin type 1 (PDF1): Protein promiscuity and expression variation within the Arabidopsis genus shed light on zinc tolerance acquisition in Arabidopsis halleri. New Phytol. 2013, 200, 820-833. [CrossRef]

33. Zai, W.S.; Ye, S.G.; Miao, L.X.; Xiong, Z.L.; Zhang, H.-L.; Ma, Y.-R.; Li, Y.-L.; Chen, Y.-B. Genome-wide identification and expression analysis of defensin genes in tomato (Solanum lycopersicum). J. Agric. Biotechnol. 2015, 23, 1588-1596. [CrossRef]

34. Wang, C.; Yao, J.; Du, X.; Zhang, Y.; Sun, Y.; Rollins, J.A.; Mou, Z. The Arabidopsis Mediator Complex Subunit16 Is a Key Component of Basal Resistance against the Necrotrophic Fungal Pathogen Sclerotinia sclerotiorum. Plant Physiol. 2015, 169, 856-872. [CrossRef]

35. Koornneef, A.; Rindermann, K.; Gatz, C.; Pieterse, C.M.J. Histone modifications do not play a major role in salicylate-mediated suppression of jasmonate-induced PDF1.2 gene expression. Commun. Integr. Biol. 2008, 1, 143-145. [CrossRef] [PubMed]

36. Thomma, B.P.H.J.; Broekaert, W.F. Tissue-specific expression of plant defensin genes PDF2.1 and PDF2.2 in Arabidopsis thaliana. Plant Physiol. Biochem. 1998, 36, 533-537. [CrossRef]

37. Yao, J.; Luo, J.; Xiao, Y.; Zhang, Z. The plant defensin gene AtPDF2.1 mediates ammonium metabolism by regulating glutamine synthetase activity in Arabidopsis thaliana. BMC Plant Biol. 2019, 19, 557. [CrossRef]

38. Luo, J.S.; Gu, T.; Yang, Y.; Zhang, Z. A non-secreted plant defensin AtPDF2.6 conferred cadmium tolerance via its chelation in Arabidopsis. Plant Mol. Biol. 2019, 100, 561-569. [CrossRef]

39. Luo, J.S.; Yang, Y.; Gu, T.; Wu, Z.; Zhang, Z. The Arabidopsis defensin gene AtPDF2.5 mediates cadmium tolerance and accumulation. Plant Cell Environ. 2019, 42, 2681-2695. [CrossRef] [PubMed]

40. Wu, Z.; Luo, J.; Han, Y.; Hua, Y.; Guan, C.; Zhang, Z. Low Nitrogen Enhances Nitrogen Use Efficiency by Triggering $\mathrm{NO}_{3}{ }^{-}$ Uptake and Its Long-Distance Translocation. J. Agric. Food Chem. 2019, 67, 6736-6747. [CrossRef] [PubMed]

41. Khan, M.I.R.; Iqbal, N.; Masood, A.; Khan, N.A. Variation in Salt Tolerance of Wheat Cultivars: Role of Glycinebetaine and Ethylene. Pedosphere 2012, 22, 746-754. [CrossRef]

42. Brown, R.L.; Kazan, K.; McGrath, K.C.; Maclean, D.J.; Manners, J.M. A role for the GCC-box in jasmonate-mediated activation of the PDF1.2 gene of Arabidopsis. Plant Physiol. 2003, 132, 1020-1032. [CrossRef]

43. Larsen, P.B.; Cancel, J.D. A recessive mutation in the RUB1-conjugating enzyme, RCE1, reveals a requirement for RUB modification for control of ethylene biosynthesis and proper induction of basic chitinase and PDF1.2 in Arabidopsis. Plant J. 2004, 38, 626-638. [CrossRef]

44. Luo, J.S.; Huang, J.; Zeng, D.L.; Peng, J.S.; Zhang, G.B.; Ma, H.L.; Guan, Y.; Yi, H.Y.; Fu, Y.L.; Han, B.; et al. A defensin-like protein drives cadmium efflux and allocation in rice. Nat. Commun. 2018, 9, 645. [CrossRef] [PubMed]

45. Tabata, R.; Sumida, K.; Yoshii, T.; Ohyama, K.; Shinohara, H.; Matsubayashi, Y. Perception of root-derived peptides by shoot LRR-RKs mediates systemic N-demand signaling. Science 2014, 346, 343-346. [CrossRef]

46. Ohkubo, Y.; Tanaka, M.; Tabata, R.; Ogawa-Ohnishi, M.; Matsubayashi, Y. Shoot-to-root mobile polypeptides involved in systemic regulation of nitrogen acquisition. Nat. Plants 2017, 3, 17029. [CrossRef]

47. Takahashi, F.; Suzuki, T.; Osakabe, Y.; Betsuyaku, S.; Kondo, Y.; Dohmae, N.; Fukuda, H.; Yamaguchi-Shinozaki, K.; Shinozaki, K. A small peptide modulates stomatal control via abscisic acid in long-distance signaling. Nature 2018, 556, 235-238. [CrossRef]

48. Chen, C.-Z.; Lv, X.-F.; Li, J.-Y.; Yi, H.-Y.; Gong, J.-M. Arabidopsis NRT1.5 Is Another Essential Component in the Regulation of Nitrate Reallocation and Stress Tolerance. Plant Physiol. 2012, 159, 1582-1590. [CrossRef]

49. Zhang, G.B.; Yi, H.Y.; Gong, J.M. The Arabidopsis Ethylene/Jasmonic acid-NRT signaling module coordinates nitrate reallocation and the trade-off between growth and environmental adaptation. Plant Cell 2014, 26, 3984-3998. [CrossRef]

50. Gojon, A. Nitrogen nutrition in plants: Rapid progress and new challenges. J. Exp. Bot. 2017, 68, 2457-2462. [CrossRef] [PubMed]

51. Masclaux-Daubresse, C.; Daniel-Vedele, F.; Dechorgnat, J.; Chardon, F.; Gaufichon, L.; Suzuki, A. Nitrogen uptake, assimilation and remobilization in plants: Challenges for sustainable and productive agriculture. Ann. Bot. 2010, 105, 1141-1157. [CrossRef] [PubMed]

52. Eren, E.; Argüello, J.M. Arabidopsis HMA2, a divalent heavy metal-transporting P(IB)-type ATPase, is involved in cytoplasmic $\mathrm{Zn}^{2+}$ homeostasis. Plant Physiol. 2004, 136, 3712-3723. [CrossRef]

53. Korenkov, V.; Hirschi, K.; Crutchfield, J.D.; Wagner, G.J. Enhancing tonoplast Cd/H antiport activity increases Cd, Zn, and Mn tolerance, and impacts root/shoot Cd partitioning in Nicotiana tabacum L. Planta 2007, 226, 1379-1387. [CrossRef] [PubMed]

54. Su, Y.; Wen, Y.; Yang, W.; Zhang, X.; Xia, M.; Zhou, N.; Xiong, Y.; Zhou, Z. The mechanism transformation of ramie biochar's cadmium adsorption by aging. Bioresour. Technol. 2021, 330, 124947. [CrossRef]

55. Gravot, A.; Lieutaud, A.; Verret, F.; Auroy, P.; Vavasseur, A.; Richaud, P. AtHMA3, a plant P1B-ATPase, functions as a Cd/Pb transporter in yeast. FEBS Lett. 2004, 561, 22-28. [CrossRef]

56. Wu, X.; Song, H.; Guan, C.; Zhang, Z. Boron alleviates cadmium toxicity in Brassica napus by promoting the chelation of cadmium onto the root cell wall components. Sci. Total Environ. 2020, 728, 138833. [CrossRef]

57. Page, V.; Feller, U. Heavy metals in crop plants: Transport and redistribution processes on the whole plant level. Agronomy 2015, 5, 447-463. [CrossRef] 
58. Stotz, H.U.; Thomson, J.; Wang, Y. Plant defensins: Defense, development and application. Plant Signal. Behav. 2009, 4, 1010-1012. [CrossRef]

59. Penninckx, I.A.M.A.; Eggermont, K.; Terras, F.R.G.; Thomma, B.P.H.J.; De Samblanx, G.W.; Buchala, A.; Metraux, J.-P.; Manners, J.M.; Broekaert, W.F. Pathogen-Induced Systemic Activation of a Plant Defensin Gene in Arabidopsis Follows a Salicylic AcidIndependent Pathway. Plant Cell 2007, 8, 2309. [CrossRef]

60. da Silva Conceição, A.; Broekaert, W.F. Plant defensins. Pathog. Proteins Plants 1999, 247-260. [CrossRef]

61. Nguyen, N.N.T.; Ranwez, V.; Vile, D.; Soulié, M.-C.; Dellagi, A.; Expert, D.; Gosti, F. Evolutionary tinkering of the expression of PDF1s suggests their joint effect on zinc tolerance and the response to pathogen attack. Front. Plant Sci. 2014, 5, 1-13. [CrossRef] [PubMed]

62. Clough, S.J.; Bent, A.F. Floral dip: A simplified method for Agrobacterium-mediated transformation of Arabidopsis thaliana. Plant J. 1998, 16, 735-743. [CrossRef] [PubMed]

63. Han, Y.; Liu, Q.; Gu, J.; Gong, J.; Guan, C.; Lepo, J.E.; Rong, X.; Song, H.; Zhang, Z. V-ATPase and V-PPase at the Tonoplast Affect $\mathrm{NO}_{3}{ }^{-}$Content in Brassica napus by Controlling Distribution of $\mathrm{NO}_{3}{ }^{-}$between the Cytoplasm and Vacuole. J. Plant Growth Regul. 2015, 34, 22-34. [CrossRef]

64. Gong, J.-M.; Lee, D.A.; Schroeder, J.I. Long-distance root-to-shoot transport of phytochelatins and cadmium in Arabidopsis. Proc. Natl. Acad. Sci. USA 2003, 100, 10118-10123. [CrossRef] [PubMed]

65. Braver, S.L.; MacKinnon, D.P.; Page, M. Levine's Guide to SPSS for Analysis of Variance; Psychology Press: New York, NY, USA, 2003; ISBN 113567440X. 